\title{
Amino- and Carboxyl-Terminal CCR5 Mutations in Brazilian HIV-1-Infected Women and Homology Model of p.L55Q CCR5 Mutant
}

\author{
Giselle Calasans de Souza Costa, ${ }^{1,2}$ Marcio Roberto T. Nunes, ${ }^{3}$ Jaqueline Goes Jesus, \\ Thiago Novaes, ${ }^{1}$ Jedson Ferreira Cardoso, ${ }^{3}$ Edivaldo Costa Sousa Júnior, ${ }^{3}$ \\ Edson de Souza Santos,' Bernardo Galvão-Castro,' Dalila Luciola Zanette, \\ Marilda de Souza Gonçalves, ${ }^{1,2}$ and Luiz Carlos Junior Alcantara ${ }^{1}$
}

\begin{abstract}
Genetic factors from an HIV-1 host can affect the rate of progression to AIDS and HIV infection. To investigate the frequency of mutations in the CCR5 gene, HIV-1 samples from infected women and uninfected individuals were selected for sequencing of the CCR5 gene regions encoding the $\mathrm{N}$ - and $\mathrm{C}$-terminal protein domains. Physicochemical CCR5 modeling and potential protein domain analysis were performed in order to evaluate the impact of the mutations found in the properties and structure of CCR5. The p.L55Q mutation in the N-terminal protein domain was observed only in uninfected individuals, with an allelic frequency of $1.8 \%$. Physicochemical analysis revealed that the p.L55Q mutation magnified the flexibility and accessibility profiles and the modeling of CCR5 structures showed resulting in a small deviation to the right, as well as a hydrophobic to hydrophilic property alteration. The p.L55Q mutation also resulted in a slight modification of the electrostatic load of this region. Additionally, three novel silent mutations were found at the C-terminal coding region among HIV-1-infected women. The results suggest that the p.L55Q mutation might alter CCR5 conformation. Further studies should be conducted to verify the role of this mutation in HIV-1 susceptibility.
\end{abstract}

\section{Introduction}

$\mathbf{T}$ HE HIV-1 ENTRY INTO TARGET CELLS requires sequential interactions between the viral envelope (env) glycoproteins, the CD4 cell receptor, and a chemokine receptor (mainly CCR5 or CXCR4) that acts as a coreceptor. ${ }^{1-3}$ CCR5-using viruses (R5-tropic strains) have been associated with the majority of new infections and predominate during the early and chronic phases of HIV-1 infection, whereas variants that use CXCR4 (X4-tropic or R5/X4-dual tropic strains) have been shown to emerge later in the infection course, usually associated with the decline of immune function and disease progression. ${ }^{1,4,5}$ It has been demonstrated that the env surface glycoprotein gp120 of R5-tropic isolates interacts with the amino terminal (N-terminal) and the second extracellular loop (ECL2) of the CCR5 coreceptor, whereas the gp120 from X4-tropic viruses interacts with the first and the second extracellular loops (ECL1 and ECL2, respectively) of the CXCR4 coreceptor.,

The mechanisms underlying HIV-1 infection and pathogenesis require a combination of viral and host factors. The
CCR5 coreceptor is essential at initial steps of HIV-1 infection, in all routes of transmission, and also has an important role in disease progression, as the CCR5 expression levels were associated with HIV-1-mediated bystander apoptosis. ${ }^{1,8-10}$ Individuals carrying the CCR5 $\Delta 32$ allele are resistant to R5- and R5/X4- HIV-1 strains. ${ }^{11}$ This mutation results in a frameshift and generates a truncated protein that cannot be exported to the cell surface, resulting in reduced expression of the receptor at the cell membrane. ${ }^{11-13}$ In addition to the CCR5 $\triangle 32$ mutation, other polymorphisms leading to posttranslational modifications, such as tyrosine sulfation and O-glycosylation of the CCR5 N-terminal domain, can affect the R5-strains entry into target cells. For instance, the tyrosine sulfations at positions 10 and 14 of the CCR5 N-terminal domain facilitate HIV-1 entry, contributing to the recognition of the CCR5 binding region by HIV-1 gp120. ${ }^{3,14-18}$ Glycosylation of CCR5 may also play a role in modulating the efficiency of HIV-1 entry at specific target cells. ${ }^{18}$ Other mutations in N-terminal domains result in amino acid alteration, such as I12L, C20S, A29S, I42F, and L55Q. ${ }^{19,20}$ In

\footnotetext{
${ }^{1}$ Centro de Pesquisa Gonçalo Moniz, Fundação Oswaldo Cruz, Salvador, Bahia, Brazil.

${ }^{2}$ Universidade Federal da Bahia, Salvador, Bahia, Brazil.

${ }^{3}$ Bioinformatic Core, Center for Technological Innovation, Evandro Chagas Institute, Pará, Brazil.
} 
Table 1. Epidemiological and Clinical Data FROM HIV-1-INFECTED WOMEN

\begin{tabular}{|c|c|}
\hline Parameters & HIV-1-infected women (\%) \\
\hline \multicolumn{2}{|l|}{ Education } \\
\hline Illiterate & $68(59.6)$ \\
\hline Primary & $12(11.0)$ \\
\hline Middle school & $1(0.7)$ \\
\hline $\mathrm{NI}^{\mathrm{a}}$ & $33(28.7)$ \\
\hline \multicolumn{2}{|l|}{ Race/color } \\
\hline White & $41(36.0)$ \\
\hline Admixture & $50(44.1)$ \\
\hline Black & $6(5.2)$ \\
\hline NI & $17(14.7)$ \\
\hline \multicolumn{2}{|c|}{ Self-reported sexual orientation } \\
\hline Heterosexual & $80(70.0)$ \\
\hline NI & $34(30.0)$ \\
\hline \multicolumn{2}{|l|}{ Transmission routes } \\
\hline Horizontal transmission & $75(66.2)$ \\
\hline Vertical transmission & $18(16.2)$ \\
\hline Injecting drug use & $3(2.2)$ \\
\hline Blood transfusion & $2(1.5)$ \\
\hline NI & $16(13.9)$ \\
\hline \multicolumn{2}{|l|}{ Antiretroviral treatment } \\
\hline Yes & $88(77.2)$ \\
\hline No & $20(17.5)$ \\
\hline NI & $6(5.3)$ \\
\hline \multicolumn{2}{|l|}{$\mathrm{CD}^{+}{ }^{+} \mathrm{T}$ cells count $($ cells $/ \mu \mathrm{l})$} \\
\hline$\geq 500$ & $47(41.2)$ \\
\hline $200-499$ & $57(50.0)$ \\
\hline$<200$ & $10(8.8)$ \\
\hline \multicolumn{2}{|l|}{ HIV-1 viral load (copies/ml) } \\
\hline$>100,000$ & $4(3.5)$ \\
\hline $10,001-100,000$ & $34(29.8)$ \\
\hline$\leq 10,000$ & $76(66.7)$ \\
\hline
\end{tabular}

${ }^{\mathrm{a}} \mathrm{NI}$, not informed.

addition, some mutations at the CCR5 carboxyl-terminal (Cterminal) domain can impact protein folding and conformation, generating an atypical protein that may not anchor properly in the cell membrane and therefore may affect virus entry. $^{21}$
To verify the presence of CCR5 gene mutations and their frequencies in HIV-1-infected women and HIV-1uninfected individuals from Bahia, Brazil, the CCR5 gene regions encoding the $\mathrm{N}$ - and $\mathrm{C}$-terminal protein domains were analyzed.

\section{Materials and Methods}

\section{Study population}

HIV-1-infected women. CCR5 gene regions encoding the $\mathrm{N}$ - and C-terminal protein domains were studied in a convenience sample of $114 \mathrm{HIV}$-1-infected women belonging to subtypes $\mathrm{B}$ and $\mathrm{C}$ who were recruited during a gynecological follow-up. These patients were followed at the Reference Center for Sexual Transmitted Disease (RCSTD)/AIDS of Feira de Santana, Bahia, Brazil, a facility that provides free patient management. In 2007, blood samples were collected from all patients who agreed to participate in the study, and were then processed at the Advanced Laboratory of Public Health (LASP)/CPqGM/FIOCRUZ in Bahia, Brazil. Clinical and epidemiological data were obtained from medical records. Informed consent was obtained from the patients and/ or the children's parents or guardians.

Control group. A total of 197 DNA samples from HIV-1-uninfected individuals were randomly selected to obtain control frequency, including 104 samples from volunteers with a median age of $25 \pm 15.2$ years, consisting of 50 males and 54 females attending the Bahia Federal University and 93 samples selected from sentinel surveillance areas of Salvador, Bahia, previously established for the investigation of various infectious diseases. $^{21}$ These 93 samples were used to study, at first, both CCR5 regions. For the study of the CCR5 gene region encoding the $\mathrm{N}$-terminal domain, all samples from the first population were also analyzed. However, for the analysis of the CCR5 gene region encoding the C-terminal domain, only 35 samples from the first population were included due to initial results showing no differences at genotypic and allelic frequencies of the CCR5 gene mutations detected when these two control populations were stratified and analyzed separately (data

Table 2. Allelic and Genotypic Frequencies of P.L55Q, c.C3765T, c.A3777T, and c.A3831G Mutations in HIV-1-INFECTED WOMEn and Uninfected Individuals

\begin{tabular}{|c|c|c|c|c|c|}
\hline \multirow[b]{2}{*}{ Mutation } & \multicolumn{3}{|c|}{ Genotypes (\%) } & \multicolumn{2}{|c|}{ Alleles (\%) } \\
\hline & Wild type & Heterozygous & Mutant & Wild type & Mutant \\
\hline \multicolumn{6}{|l|}{ p.L55Q } \\
\hline HIV-1 positive & $114(100)$ & $0(0.0)$ & $0(0.0)$ & $228(100)$ & $0(0.0)$ \\
\hline HIV-1 negative & $190(96.4)$ & $7(3.6)$ & $0(0.0)$ & 387 (98.2) & $7(1.8)$ \\
\hline \multicolumn{6}{|l|}{ c.C3765T } \\
\hline HIV-1 positive & $106(92.5)$ & $8(7.5)$ & $0(0.0)$ & $220(96.5)$ & $8(3.5)$ \\
\hline HIV-1 negative & $123(96.1)$ & $5(3.9)$ & $0(0.0)$ & $251(98.0)$ & $5(2.0)$ \\
\hline \multicolumn{6}{|l|}{ c.A3777T } \\
\hline HIV-1 positive & $113(99.2)$ & $1(0.8)$ & $0(0.0)$ & 227 (99.6) & $1(0.4)$ \\
\hline HIV-1 negative & $124(96.8)$ & $4(3.2)$ & $0(0.0)$ & $252(98.4)$ & 4 (1.6) \\
\hline \multicolumn{6}{|l|}{ c.A3831G } \\
\hline HIV-1 positive & 113 (99.2) & $1(0.8)$ & $0(0.0)$ & 227 (99.6) & $1(0.4)$ \\
\hline HIV-1 negative & $128(100)$ & $0(0.0)$ & $0(0.0)$ & $256(100)$ & $0(0.0)$ \\
\hline
\end{tabular}


FIG. 1. The final model of the stable structure of mutant CCR5 (p.L55Q mutation). The HIV-1 binding site is featured. Right, focus on the p.L55Q mutation region. Color images available online at www.liebertpub.com/aid

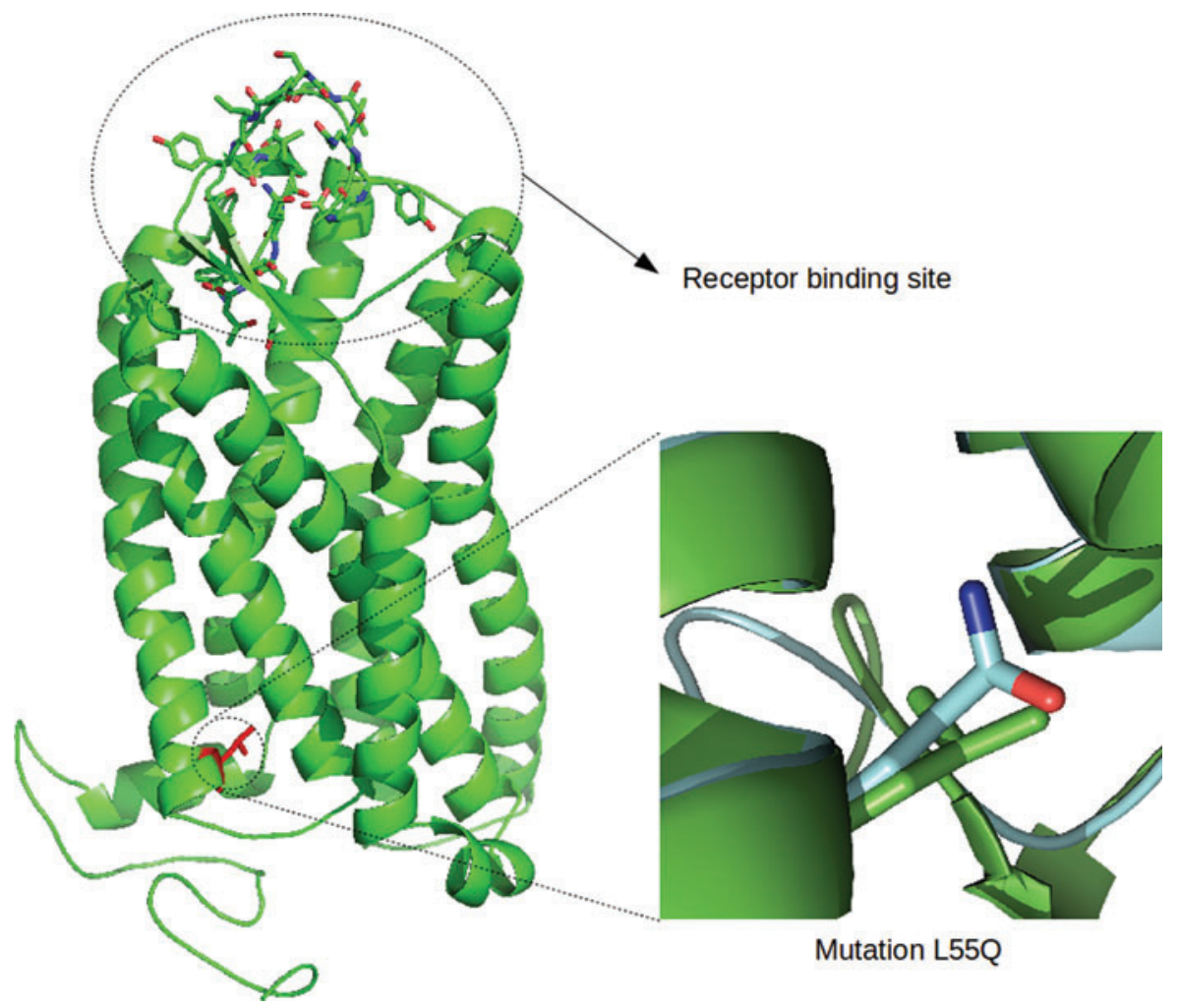

not shown). For this reason, the uninfected individuals from the two control groups were compiled and studied as the same reference group.

The local ethical committee's approval was obtained and all subjects provided written informed consent.

\section{DNA extraction and mutation detection}

Genomic DNA was extracted from peripheral blood mononuclear cells (PBMCs) using the QIAamp DNA Blood Mini Kit (QIAGEN Inc., Valencia, CA). The analyses of the

\section{Ramachandran Plot}
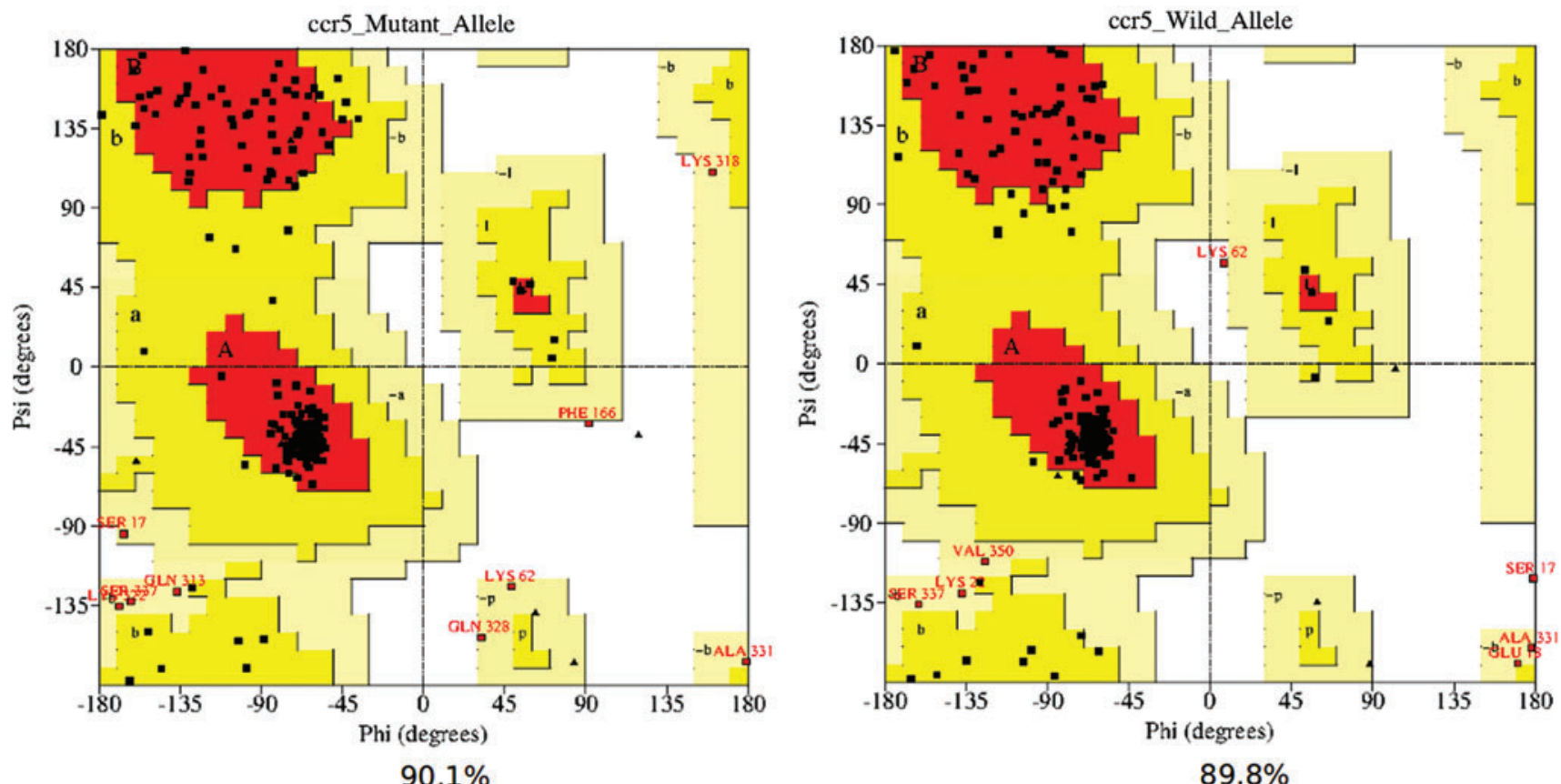

FIG. 2. Validation of the model using the Ramachandran plot computed with the PROCHECK program with $90.1 \%$ and $89.8 \%$ of the residues from the mutant and wild-type models, respectively, in favored and allowed regions. Color images available online at www.liebertpub.com/aid 
$\mathrm{N}$ - and C-terminal regions of the CCR5 protein were performed through PCR amplification (300 bp and $344 \mathrm{bp}$, respectively) followed by sequencing. The primers constructed for these analyses were 5'TTTGCATTCATGGAGGGCA3' and 5'TGGCCAGGTTGAG CAGGTAG3' for the N-terminal region and 5'TCTCTTCTGGGCTCCCTACA3' and 5'CCAG CCCACTTGAGTCCGTG3' for the C-terminal region. All sequences obtained were analyzed with the SeqScape program (Applied Biosystems) and the observed nucleotide variations were confirmed using the BioEdit ${ }^{22}$ and GeneDoc ${ }^{23}$ programs.

\section{Physicochemical and potential protein domain analyses}

To investigate the possible impact of mutations, the physicochemical analysis of the missense mutations observed in the sequences was performed using Network Protein Sequence Analysis (NPSA) (http://npsa-pbil.ibcp.fr/). ${ }^{24}$ Posttranslational modification sites were identified using the Prosite tool implemented in GeneDoc software. ${ }^{22}$ The potential protein domain analysis was performed using the Pfam database. ${ }^{25}$ Finally, the SWISS-MODEL online tool (http:// swissmodel.expasy.org/ $)^{26}$ was used as a fully automated protein structure homology-modeling server to infer the impact of the amino acid changes at the protein secondary structure.

\section{Homology modeling of CCR5}

The Homology Model of Human CCR5 was generated using Modeller 9.10 software26 with the crystal structure (PDB: 2KS9, 3ODU, and 4MBS) as template chosen from the PDB BLAST hit (http://www.rcsb.org/pdb/home/home). The obtained model was validated using Procheck software. ${ }^{27}$

\section{Statistical methods}

The allelic frequencies were estimated by direct allele counting. Conformity with Hardy-Weinberg equilibrium and the existence of linkage disequilibrium were tested using Genepop v.3.4. ${ }^{28}$ The heterogeneity between population samples was evaluated by Fisher's exact test or by $\chi^{2}$ test using the BioEstat v.5.0 program. ${ }^{29}$ The median HIV-1 viral load and TCD4 cell counting in infected patients were also calculated using the BioEstat v.5.0 program. A $p$-value of $<0.05$ was considered statistically significant.

\section{Results}

The HIV-1-infected individuals consisted of 114 women with ages ranging from 20 to 73 years (mean $=37.9$ years). The epidemiological and clinical data are shown in Table 1. This population was highly heterogeneous regarding the time of antiretroviral (ARV) treatment, the appearance of HIV-1 constitutional symptoms, viral load, and TCD4 cell counting. The median HIV-1 viral load was $754 \pm 40.02$ copies $/ \mathrm{ml}$ and the median TCD4 cell counting was $437 \pm 99.87$ cells $/ \mu \mathrm{l}$. Eighty-eight (77.2\%) patients were under ARV therapy and $20(17.5 \%)$ were therapy naive. Six patients $(5.3 \%)$ did not have available data in their medical records.

The analysis of the CCR5 N-terminal domain sequences revealed the missense mutation at position 165 of the CCR5 gene in seven $(3.6 \%)$ samples from uninfected individuals (allelic frequency of $1.8 \%$ ) characterized by the substitution of a thymine to an adenine nucleotide, which resulted in an amino acid change of a leucine to a glutamine (p.L55Q mutation) at position 55 of the CCR5 protein. The p.L55Q mutation was not observed in HIV-1-infected individuals (Table 2) and the physicochemical analysis revealed that this mutation magnified the flexibility and accessibility profiles (data not shown). When the mutant protein sequence was subjected to potential protein domain analysis to determine if the p.L55Q mutation had changed any signature into the Nterminal protein domain, no modification was observed. Also, this mutation did not change any posttranslational modification site and did not influence the prediction of the protein secondary structure.

The Homology Model of Human CCR5 generated the final stable p.L55Q CCR5 structure (Fig. 1). After the refinement process, validation of the CCR5 models with mutant and wild-type residues was carried out using Ramachandran plot calculations. Altogether, $91.1 \%$ and $89.8 \%$ of the residues from mutant and wild-type models, respectively, were in favored and allowed regions, demonstrating that both models have a good stereochemistry quality (Fig. 2). Overlapped

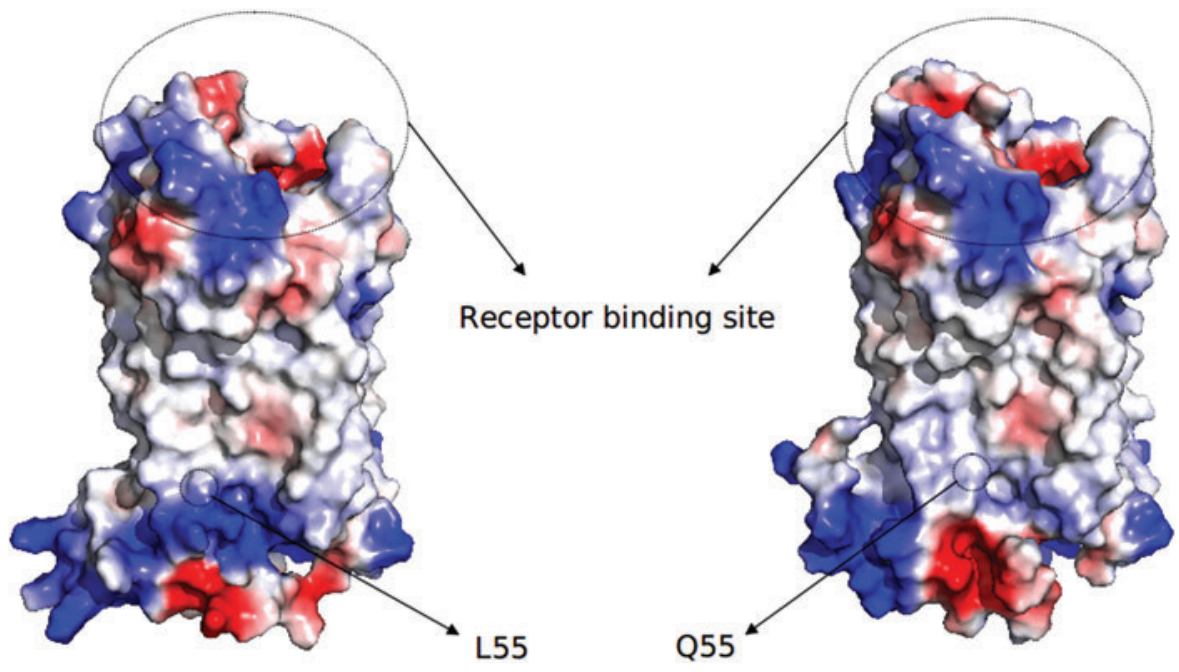

FIG. 3. Electrostatic load of the wild-type (L55) and mutant (Q55) models. HIV-1 binding site, L55 and Q55 alleles are featured. Color images available online at www .liebertpub.com/aid 
structures showed that there was a small deviation to the right as well as a hydrophobic to hydrophilic property alteration (Fig. 1). The p.L55Q mutation resulted in a small modification of the electrostatic load of this region (Fig. 3).

The analysis of the CCR5 gene region encoding the Cterminal protein domain revealed three novel silent mutations present in HIV-1-infected women and uninfected individuals (c.3765C $>\mathrm{T}$, c.3777A $>\mathrm{T}$, and c.3831A $>\mathrm{G}$ ), which characterized this CCR5 gene region as more divergent than the encoding region of the $\mathrm{N}$-terminal protein domain. Except for the c.3831A $>\mathrm{G}$ mutation, the other mutations were considered as polymorphic sites in the studied populations (Table 2).

Genotypic and allelic frequencies of the analyzed sites are shown in Table 1 and did not differ significantly from the frequencies expected under Hardy-Weinberg equilibrium $\left(p=1.00, \chi^{2}=0.0001\right)$. Linkage disequilibrium was not observed between any of the analyzed mutations when HIV-1infected women and uninfected individuals were compared $\left(p=1.00, \chi^{2}=0.0001\right)$.

\section{Discussion}

Viral and host factors have been associated with variations in the infection susceptibility and postinfection replication level in different HIV-1-infected individuals. Some of these host factors have already been identified as determinants in HIV-1 infection susceptibility and AIDS progression. However, it is possible that other nonidentified host factors are related to infection control, emphasizing that human genetic variation studies can contribute to a better understanding of HIV-1 infection and AIDS progression mechanisms. ${ }^{13,30-33}$

In this context, many studies have demonstrated an association between mutations in human genes, disease manifestation, and viral infection influence. ${ }^{34-36}$ Regarding HIV-1 infection, the chemokine receptor CCR5 acts as the coreceptor for R5-tropic strains and some mutations in the promoter and the encoding regions of the CCR5 gene influence virus infection and/or AIDS progression. These mutations could affect CCR5 protein expression in the cell surface leading to a high or low protein production phenotype and could also change the protein structure, which could be related to its functionality and affect its activity at the cell membrane. In addition, the CCR5 protein undergoes posttranslational modifications at specific amino acids at the amino and carboxyl domains that are important for the interaction between this coreceptor and HIV-1 gp120, leading to membrane fusion and cell infection. Therefore, CCR5 gene mutations that change $\mathrm{N}$ - and $\mathrm{C}$-terminal amino acids could interfere in the ability of CCR5 to bind gp120 and affect HIV-1 entry. ${ }^{10,37-39}$ In this regard, this is the first study to analyze mutations in the CCR5 gene regions encoding the $\mathrm{N}$ - and C-terminal protein domains in HIV-1-infected individuals in a Brazilian population.

The p.L55Q mutation, observed in the N-terminal domain of the CCR5 protein, is characterized by a change from a nonpolar amino acid (leucine or L) to a polar amino acid (glutamine or Q), which did not cause changes in any posttranslational modification site. The physicochemical analysis revealed that the mutated allele p.L55Q may create a more flexible protein domain than the wild-type allele, which indicates that the protein may present a greater number of structure conformations. Also, the modeling results demonstrated that this mutation altered the CCR5 3D structure. Altogether, these results could indicate that since this mutation is placed next to the region that interacts with the HIV-1 gp120, comprising amino acids 2 to 18 of the N-terminal domain, this amino acid change interferes in the CCR5 Nterminal conformation, possibly affecting the interaction region and gp120 binding.

In our study, the p.L55Q mutation was observed only in uninfected individuals, suggesting that the 55 amino acid change in the CCR5 N-terminal domain could interfere with HIV-1 entry through the CCR5 coreceptor. Carrington and collaborators showed that L55Q/CCR5- $\Delta 32$ heterozygotes were found on infected and uninfected individuals and did not alter the progression to AIDS. ${ }^{19}$ Despite this, we suggest that it would be very elucidative to study this mutation in groups of exceptional individuals who deviate from the expected response to HIV exposure, such as long-term nonprogressors (LTNP), who maintain stable TCD4 cell levels and low viral load for 10 or more years; fast progressors (FP), who cannot control viremia and develop AIDS within 3 years of infection $^{40}$; and elite controllers (EC), who control HIV replication under 50 copies $/ \mathrm{ml}^{41,42}$ Only one study was performed in this line, by Young and colleagues, who did not find L55Q in a group of highly exposed, persistently seronegative (HEPS) women in Thailand. ${ }^{43}$

The three mutations $(\mathrm{c} .3765 \mathrm{C}>\mathrm{T}, \mathrm{c.} 3777 \mathrm{~A}>\mathrm{T}$, and c. $3831 \mathrm{~A}>\mathrm{G}$ ) observed in the $C C R 5$ gene region encoding the C-terminal protein domain do not cause any amino acid change in protein sequence. The number of mutations detected at this region of the CCR5 gene shows that it is more divergent than the encoding region of the $\mathrm{N}$-terminal protein domain, suggesting that the C-terminal CCR5 domain suffers a minor positive selective pressure when compared to the $\mathrm{N}$ terminal domain, probably due to its localization in the cytoplasmatic side of the cell.

The results presented here suggest that the p.L55Q mutation, observed in the CCR5 N-terminal domain of uninfected individuals, could have a protective role in HIV-1 infection. Despite this, all the available studies failed to find any actual impact of the p.L55Q mutation on HIV entry into cells. Our analysis provides additional reasons to further investigate this and other polymorphisms in the $\mathrm{N}$ - and $\mathrm{C}$-terminal CCR5 domains that might contribute to a better evaluation of the major role of CCR5 in HIV-1 infection, as this protein becomes an attractive target for therapeutic development against virus infection.

\section{Acknowledgments}

This work was supported by grants from the Brazilian Ministry of Health STD/AIDS Program, CNPq, FBDC, and FIOCRUZ.

\section{Author Disclosure Statement}

No competing financial interests exist.

\section{References}

1. Gorry PR and Ancuta P: Coreceptors and HIV-1 pathogenesis. Curr HIV/AIDS Rep 2011;8(1):45-53.

2. Nazari R and Joshi S: CCR5 as target for HIV-1 gene therapy. Curr Gene Ther 2008;8(4):264-272. 
3. Choe H, Li W, Wright PL, et al.: Tyrosine sulfation of human antibodies contributes to recognition of the CCR5 binding region of HIV-1 gp120. Cell 2003;114:161-170.

4. Connor RI, Sheridan KE, Ceradini D, et al.: Change in coreceptor use correlates with disease progression in HIV1-infected individuals. J Exp Med 1997;185:621-628.

5. Regoes RR and Bonhoeffer S: The HIV coreceptor switch: A population dynamical perspective. Trends Microbiol 2005;13(6):269-277.

6. Brelot A, Heveker N, Pleskoff O, et al.: Role of the first and third extracellular domains of CXCR4 in HIV coreceptor activity. J Virol 1997;7:4744-4751.

7. Lu Z, Berson JF, Chen Y, et al.: Evolution of HIV-1 coreceptor usage through interactions with distinct CCR5 and CXCR4 domains. Proc Natl Acad Sci USA 1997;94:64266431.

8. Dragic T, Litwin V, Allaway GP, et al.: HIV-1 entry into $\mathrm{CD}^{+}$cells is mediated by the chemokine receptor CCCKR-5. Nature 1996;381:667-673.

9. Mogensen TH, Melchjorsen J, Larsen CS, and Paludan SR: Innate immune recognition and activation during HIV infection. Retrovirology 2010;7:54.

10. Joshi A, Nyakeriga AM, Ravi R, and Garg H: HIV ENV glycoprotein-mediated bystander apoptosis depends on expression of the CCR5 co-receptor at the cell surface and ENV fusogenic activity. J Biol Chem 2011;286:3640436413.

11. Samson M, Libert F, Doranz BJ, et al.: Resistance to HIV-1 infection in caucasian individuals bearing mutant alleles of the CCR-5 chemokine receptor gene. Nature 1996;382: $722-725$.

12. O'Brien TR, Winkler C, Dean M, et al.: HIV-1 infection in a man homozygous for CCR5 32 . Lancet 1997;349: 1219.

13. Liu R, Paxton WA, Choe S, et al.: Homozygous defect in HIV-1 co-receptor accounts for resistance of some multiply-exposed individuals to HIV-1 infection. Cell 1996;86: 367-377.

14. Blanpain C, Doranz BJ, Vakili J, et al.: Multiple charged and aromatic residues in CCR5 amino-terminal domain are involved in high affinity binding of both chemokines and HIV-1 Env protein. J Biol Chem 1999;274:34719-34727.

15. Farzan M, Choe H, Vaca L, et al.: A tyrosine-rich region in the $\mathrm{N}$ terminus of CCR5 is important for human immunodeficiency virus type 1 entry and mediates an association between gp 120 and CCR5. J Virol 1998;72:1160-1164.

16. Rabut GE, Konner JA, Kajumo F, et al.: Alanine substitutions of polar and nonpolar residues in the amino-terminal domain of CCR5 differently impair entry of macrophageand dualtropic isolates of human immunodeficiency virus type 1. J Virol 1998;72:3464-3468.

17. Farzan M, Mirzabekov T, Kolchinsky P, et al.: Tyrosine sulfation of the amino terminus of CCR5 facilitates HIV-1 entry. Cell 1999;96:667-676.

18. Acharya P, Dogo-Isonagie C, Lam SN, et al.: Structurebased identification and neutralization mechanism of tyrosine sulfation mimetics that inhibit HIV-1 entry. ACS Chem Biol 2011;6(10):1069-1077.

19. Carrington M, Kissner T, Gerrard B, et al.: Novel alleles of the chemokine-receptor gene CCR5. Am J Hum Genet 1997; 61:1261-1267.

20. Ansari-Lari M, Liu X-M, Metzker M, et al.: The extent of genetic variation in the CCR5 gene. Nat Genet 1997;16: 221-222.
21. Zhang M, Gaschen B, Blay W, et al.: Tracking global patterns of $\mathrm{N}$-linked glycosylation site variation in highly variable viral glycoproteins: HIV, SIV and HCV envelopes and influenza hemagglutinin. Glycobiology 2004;14(12): 1229-1246.

22. Teixeira MG, Barreto ML, Costa MCN, et al.: Sentinel areas: A monitoring strategy in public health. Caderno de Saúde Pública 2002;18(5):1189-1195.

23. Hall TA: BioEdit: A user-friendly biological sequence alignment editor and analysis program for Windows 95/98/ NT. Nucleic Acids Symp Ser 1999;41:95-98.

24. Nicholas KB, Nicholas HB Jr, and Deerfield DW II: GeneDoc: Analysis and visualization of genetic variation. EMBNEW.NEWS 1997;4:14.

25. Combet C, Blanchet C, Geourjon C, and Deléage G: NPS@: Network Protein Sequence Analysis. TIBS 2000; 25(3):147-150.

26. Finn RD, Mistry J, Tate $\mathrm{J}$, et al.: The Pfam protein families database. Nucl Acids Res 2010;38:211-222.

27. Parker JMR, Guo D, and Hodges RS: New hydrophilicity scale derived from high-performance liquid chromatography peptide retention data: Correlation of predicted surface residues with antigenicity and $\mathrm{X}$-ray-derived accessible sites. Biochemistry 1986;25:5425-5431.

28. Sali A and Blundell TL: Comparative protein modelling by satisfaction of spatial restraints. J Mol Biol 1993;234:779815.

29. Laskowski RA, MacArthur MW, Moss DS, and Thornton JM: PROCHECK-a program to check the stereochemical quality of protein structures. J Appl Cryst 1993;26:283291.

30. Raymon M and Rousset F: GENEPOP (version 1.2): Population genetics software for exact tests and ecumenicism. J Hered 1995;86:248-249.

31. Ayres M, Ayres M Jr, Ayres DL, and Santos AS: BioEstat Versão 5.0. Sociedade Civil Mamiraua, MCT-CNPq, Belém, Pará, Brasil, 2005.

32. Rogers F, Lim SY, Sundsvold TJ, et al.: Variability in a dominant block to SIV early reverse transcription in rhesus monkey cells predicts in vivo viral replication and time to death. Virol J 2010;7:79-90.

33. Kawashima Y, Pfafferot K, Frater J, et al.: Adaptation of HIV-1 to human leukocyte antigen class I. Nature 2009;458 (7238):641-645.

34. Schmitz JE, Kuroda MJ, Santra S, et al.: Control of viremia in simian immunodeficiency virus infection by CD8+ lymphocytes. Science 1999;283(5403):857-860.

35. Sabouri AH, Saito M, Lloyd AL, et al.: Polymorphism in the interleukin-10 promoter affects both provirus load and the risk of human $\mathrm{T}$ lymphotropic virus type I-associated myelopathy/tropical spastic paraparesis. J Infect Dis 2004;190:1279-1285.

36. Yoshikawa T, Kitamura A, Hasegawa G, et al.: Interleukin6 polymorphism $(634 \mathrm{C} / \mathrm{G})$ in the promotor region and the progression of diabetic nephropathy in type 2 diabetes. Diabet Med 2002;19:1000-1005.

37. Licastro F, Grimaldi LM, Bonafe M, et al.: Interleukin-6 gene alleles affect the risk of Alzheimer's disease and levels of the cytokine in blood and brain. Neurobiol Aging 2003;24(7):921-926.

38. Slater-Handshy T, Droll DA, Fan X, et al.: HCV E2 glycoprotein: Mutagenesis of N-linked glycosylation sites and its effects on E2 expression and processing. Virology 2004;319:36-48. 
39. O'Brien SJ and Moore JP: The effect of genetic variation in chemokines and their receptors on HIV transmission and progression to AIDS. Immunol Rev 2000;177:99-111.

40. Farzan M, Vasilieva N, Schnitzler CE, et al.: A tyrosinesulfated peptide based on the $\mathrm{N}$ terminus of CCR5 interacts with a CD4-enhanced epitope of the HIV-1 gp120 envelope glycoprotein and inhibits HIV-1 entry. J Biol Chem 2000;275(43):33516-33521.

41. O'Brien SJ and Nelson GW: Human genes that limit AIDS. Nature Genet 2004;36:565-574.

42. Walker BD: Elite control of HIV Infection: Implications for vaccines and treatment. Top HIV Med 2007;15:134-136.

43. Yang C, Li M, Limpakarnjanarat K, et al.: Polymorphisms in the CCR5 coding and noncoding regions among HIV type 1-exposed, persistently seronegative female sex- workers from Thailand. AIDS Res Hum Retroviruses 2003;19(8):661-5.

Address correspondence to: Luiz Carlos Junior Alcantara Laboratório de Hematologia, Genética e Biologia Computacional Centro de Pesquisa Gonçalo Muniz. Fundação Oswaldo Cruz

Rua Waldemar Falcão 121

Candeal, Salvador, Bahia 40296-610

Brazil

E-mail: lalcan@bahia.fiocruz.br 